\title{
Religión y política en América Latina: la confrontación entre Juan Pablo II y Ernesto Cardenal en $1983^{1}$
}

\author{
Anuario Latinoamericano \\ Ciencias Políticas \\ y Relaciones Internacionales \\ vol. 3, 2016 \\ pp. 19-34
}

DOI: 10.17951/al.2016.3.19

\section{Religion and politics in Latin America: the confrontation between John Paul II and Ernesto Cardenal in 1983}

\author{
Armando Lampe ${ }^{2}$ \\ INSTITUT THEOLOGIE INTERKULTURELL \\ UNIVERSIDAD DE FRANKFURT \\ ALEMANIA \\ $\triangle$ armando.lampe@gmail.com
}

\begin{abstract}
RESUMEN
El artículo analiza las complicadas relaciones entre religión y politica en América Latina, estudiando un caso concreto: el conflicto entre el sacerdote-político Ernesto Cardenal y el papa Juan Pablo II en 1983 durante el gobierno sandinista. El nuevo Código de Derecho Canónico quedó promulgado por el papa Juan Pablo II en enero de 1983, donde por primera vez en la historia de la Iglesia católica se decreta una prohibición absoluta a los sacerdotes para asumir cargos en el ejercicio del poder civil, ya sea en el poder ejecutivo o en el legislativo. Dos meses después, en marzo de 1983, el papa Juan Pablo II reprocha públicamente a Ernesto Cardenal su desobediencia al nuevo Código de Derecho Canónico y lo suspende como sacerdote. El artículo muestra que la decisión de la autoridad eclesial refleja una doctrina política que no es relevante para el caso de Nicaragua de entonces.
\end{abstract}

\footnotetext{
1 El presente trabajo fue realizado gracias al apoyo financiero de Alexander von Humboldt Foundation en 2015.

2 Nacido en Aruba en 1958, hizo estudios de Teología en la Universidad Católica de Nijmegen, Holanda, de Sociología en la Universidad Iberoamericana de la Ciudad de México, y de Estudios Latinoamericanos en la Universidad Nacional Autónoma de México. Tiene doctorado en Ciencias Sociales y Culturales por la Universidad Libre de Amsterdam (1988). El presente trabajo forma parte de una investigación más amplia sobre sacerdotes-políticos en la historia de la Iglesia católica, apoyada por la Fundación Alexander von Humboldt. Algunas de sus publicaciones son História do Cristianismo no Caribe, Petrópolis, Ed. Vozes, 1995 (traducido al español como Breve historia del cristianismo en el Caribe, Chetumal, Universidad de Quintana Roo, 1997); Mission or Submission? Moravian and Catholic Missionaries in the Dutch Caribbean during the Nineteenth Century, Göttingen, Vandenhoeck \& Ruprecht, 2000 y Christianity in the Caribbean. Essays on Church History, Kingston, The University of the West Indies Press, 2001.
} 
Dossier América Latina: política y religión
PALABRAS CLAVE: religión y política, sacerdote-politico, Nicaragua, Ernesto Cardenal, Juan Pablo II.

\section{ABSTRACT}

The article explores the difficult subject of religion and politics in Latin America by studying a concrete case: the conflict between the priest-politician Ernesto Cardenal and the late Pope John Paul II in 1983, during the Sandinista government. The new Canon Law was passed in January 1983 by John Paul II and for the first time in church history it strictly prohibited priests to exercise civil power, either in the legislative or the executive power. Two months later, in March 1983, John Paul II rebuked publicly Ernesto Cardenal for being disobedient to the Canon Law and suspended him as a priest. The article shows that the decision of the church highest authority was a reflection of a political doctrine that was not relevant for Nicaragua of those years.

KEYWORDS: religion and politics, priest-politician, Nicaragua, Ernesto Cardenal, John Paul II.

\section{Introducción}

El año 1983 fue importante para la historia de la religión y la política. El nuevo Código de Derecho Canónico quedó promulgado por el papa Juan Pablo II en enero de 1983, donde por primera vez en la historia de la Iglesia católica se decreta una prohibición absoluta a los sacerdotes para asumir cargos en el ejercicio del poder civil, ya sea en el poder ejecutivo o en el legislativo (Lampe 2013: 223-239). Dos meses después, en marzo de 1983, el papa Juan Pablo II reprocha públicamente a Ernesto Cardenal su desobediencia al nuevo Código de Derecho Canónico. En el presente estudio trato de entender ese choque de pensamiento entre Juan Pablo II, la máxima autoridad de la Iglesia católica, y Ernesto Cardenal, un sacerdote-político dentro de la corriente de la teología de liberación.

En África, en 1980, el papa Juan Pablo II dijo a sacerdotes africanos:

Por el ejemplo de su amor al prójimo el pueblo cristiano debe mantener la unidad que está bajo su cuidado. Deja la responsabilidad política a los que tienen ese encargo. Su participación es más elevada. Son líderes, pero en otro sentido y de otra manera, porque participan en el sacerdocio de Cristo. Su compromiso está a nivel de la fe y de la moral ... Aquí se espera de ustedes que prediquen por medio de la palabra valiente y del ejemplo vivo. (Lemieux 1982: 465-470)

En marzo de 1983 todo el mundo pudo ver a través de las pantallas de televisión la consecuencia práctica de esa prohibición durante la visita de Juan 
Pablo II a Nicaragua. El propio Ernesto Cardenal escribió sobre su confrontación con Juan Pablo II en el aeropuerto de Managua el 4 de marzo de 1983:

Después de todos los saludos de protocolo (...) el Papa le preguntó a Daniel [Ortega] que lo llevaba del brazo, si podía saludar también a los ministros (...) y se dirigió a nosotros. Flanqueado por Daniel y el cardenal Casaroli, fue dando la mano a los ministros, y cuando se acercó (...) hice lo que en ese caso habia previsto hacer (...) y fue quitarme reverentemente la boina, y doblar la rodilla para besarle el anillo. No permitió él que se lo besara, y blandiendo el dedo como si fuera un bastón me dijo en tono de reproche: 'Usted debe regularizar su situación'. Como no contesté nada, volvió a repetir la brusca admonición. (Cardenal 2005: 288-290)

La interpretación que hizo Ernesto Cardenal de ese conflicto en 1983 fue así:

Y la verdad es que lo que más le disgustaba al Papa de la revolución de Nicaragua es que fuera una revolución que no perseguía la Iglesia. El hubiera querido un régimen como el de Polonia, que era anticatólico en un país mayoritariamente católico, y por lo tanto impopular. Lo que menos quería era una revolución apoyada masivamente por los cristianos como la nuestra, en un país cristiano, y por lo tanto una revolución muy popular. Y lo peor de todo para él es que fuera una revolución con sacerdotes.

El papa Juan Pablo II leía la realidad latinoamericana con los ojos polacos y no podía entender a Nicaragua: Juan Pablo II era anticomunista y pensaba que la revolución de Nicaragua era comunista. Hay un elemento de verdad en ese análisis de Ernesto Cardenal. Juan Pablo II apoyó incondicionalmente al sindicato Solidaridad en Polonia y su papado jugó un papel importante en la caída del comunismo por 1990 (Coppa 2008: 159). Juan Pablo II se quejaba del marxismo en la teología de la liberación en su visita a Brasil en octubre de 1991 y recordó al clero que la política no es la misión de la Iglesia y con mano dura castigó a los cuatro sacerdotes que eran ministros en el gobierno sandinista (Coppa 2008: 190). Eso no quita que la misión de Juan Pablo II fue política: colaboró de una forma inusual con el Presidente Ronald Reagan de los Estados Unidos (Kent, Pollard 1994: 11-24). No sólo Juan Pablo II y Ronald Reagan colaboraban por ser anticomunistas, que apoyaban la contrarevolución dirigida contra el gobierno sandinista, sino había también otro interés de por medio. El Vaticano negociaba con Reagan el reestablecimiento de las completas relaciones diplomáticas entre el Vaticano y los Estados Unidos, que finalmente fue firmado por Reagan el 22 de noviembre de 1983, a pesar de que Reagan era protestante, pero él fue en primer lugar anticomunista (Fogarty 1994: 221-243, 239-240).

El triunfo de la revolución sandinista en 1979 significaba una crisis del dominio de los Estados Unidos en Centroamérica y tenía pues un significado geopolítico mundial. Había otra característica que hacía la revolución san-
Religión y política en América Latina: la confrontación entre Juan Pablo II y Ernesto Cardenal en 1983

Armando Lampe 
Dossier América Latina: política y religión dinista tan peligrosa: contaba con la participación masiva de cristianos y sacerdotes, y la revolución adquirió una dimensión religiosa. El embajador de Nicaragua ante el Vaticano entre 1980 y 1990, precisamente en ese período del conflicto sobre los cuatro sacerdotes, escribió acertadamente: "It was the participation of Christians in a socialist revolution having the character of alternative politics, in an area of extreme strategic interest, which influenced, determined and conditioned the diplomatic activity of the Vatican. This view should inform any analysis of the relationship of the Vatican to the Nicaraguan revolution." (Peter 1994: 245-251)

Pero Juan Pablo II aplicó esa regla no sólo en Nicaragua y en América Latina, sino también en los Estados Unidos de América. El padre Robert F. Drinan S. J. tuvo que renunciar a su cargo que ocupaba en el Congreso desde 1970 y a la candidatura de reelección para el Congreso de 1980 por orden del General de la Compañía de Jesús, el padre Arrupe, el 27 de abril de 1980 (Liedhegener 1960: 69). El propio Padre Arrupe declaró que actuó en el caso de Drinan bajo instrucción explícita de Juan Pablo II (Higgins 1982: 527-531). Probablemente fue esa colaboración entre Juan Pablo II y Reagan que llevó al papa a sacrificar esa 'pieza' que llevaba el nombre de Drinan, aunque es imposible saber con exactitud los motivos de Juan Pablo II en su acción contra Drinan hasta que los archivos del Vaticano y los archivos eclesiásticos estén abiertos para la investigación (Fogarty 1985: 36). Veamos en detalle no el caso de Drinan sino el de Ernesto Cardenal.

Ernesto Cardenal nació el 20 de enero de 1925 en Granada, Nicaragua, y fue alumno del colegio de jesuitas. Estudió de 1943 a 1947 filosofía y literatura en la Universidad Nacional Autónoma de México y de 1947 a 1949 en Columbia University en Nueva York. Viajó después por Europa para completar su formación antes de regresar a Nicargua en 1950. En 1954 participó en la así llamada Rebelión de Abril contra la dictadura de Somoza, que fracasó rotundamente, y Ernesto Cardenal toma el camino del exilio (Cardenal 1980: 106. ${ }^{3}$ En 1957, después de una experiencia mística, empieza su vida religiosa en el monasterio Gethsamani de los Trapenses en Kentucky, Estados Unidos, bajo la guía del escritor místico Thomas Merton. Por instrucción de Merton deja el monasterio para fundar una comunidad monástica en Nicaragua, pero para cumplir esa misión tenía que ser ordenado sacerdote (Daydí-Tolson 1998). Entró entonces al seminario en Colombia y al terminar su estudio de teología fue ordenado sacerdote en 1965 e inmediatamente después, en 1966, funda la comunidad religiosa de Solentiname. En esa época surge la teología de la liberación y Cardenal se vuelve uno de los exponentes más famosos de esa corriente teológica. Se trata de una huída del mundo lleno de injusticia para construir con los pobres de la tierra un mundo justo, un mundo lleno de comunismo, que en las palabras

3 Ernesto Cardenal menciona que por la vía contemplativa llegó a su compromiso político, aunque se contradice, porque antes de entrar al monasterio ya fue un activista político. 
de Ernesto Cardenal es el nombre del Reino de Dios en la tierra (GonzálezBalado 1978: 29). Se incorpora al movimiento guerillero Frente Sandino de Liberación Nacional (FSLN), y su comunidad es destruida por Somoza en 1977, por lo que tiene que optar nuevamente por el camino del exilio. Cuando triunfa la revolución contra Somoza el 1 de julio de 1979, Cardenal se vuelve ministro de Cultura, cargo que ocupa hasta 1988. En 1990, el FSLN pierde la elección e inicia una etapa de corrupción de líderes del FSLN. En 1994, Cardenal abadona al partido político sandinista y se dedica de lleno a su trabajo literario. Ernesto Cardenal recibió en 1980, en Frankfurt, el Premio de la Paz del Comercio Librero Alemán (Friedenspreis des Deutschen Buchhandels, Peace Prize of the German Book Trade) y el "laudatio" estuvo a cargo del profesor Johann Babtist Metz, el creador de la teología política. En 2014, recibió en Berlín el Premio Theodor Wanner, para el diálogo intercultural, auspiciado por el secretario de Relaciones Exteriores del gobierno alemán y el "laudatio" estuvo a cargo del presidente del Parlamento alemán, el profesor Norbert Lammert. Cardenal recibió otros importantes premios literarios, pero aquí no es objeto de estudio su obra literaria, sino su trabajo como sacerdote-político (Urdanivia Bertarelli 1984).

El 1 de junio de 1981 los obispos de Nicaragua dieron un ultimátum a Ernesto Cardenal y los otros tres sacerdotes que ocupaban cargos de ministros en el gobierno sandinista con las siguientes palabras: "o dejan su cargo de ministro en el gobierno o serán castigados". El 8 de junio los sacerdotes responden que no dejarán el cargo. Para el día 30 Cardenal Casaroli, el Secretario de Estado del Vaticano, interviene en el conflicto para buscar una solución y propone un diálogo entre los obispos y los sacerdotes, mismo que se realizó el 15 de julio donde se llegó a la resolución de que se aplicara la cláusula de la excepción que contempla el Derecho Canónico de 1917. Es decir, tienen entonces el permiso de la jerarquía para asumir el cargo de ministro en el gobierno sandinista, porque se trata de una situación excepcional, y por lo tanto los sacerdotes no deben abandonar el sacerdocio, pero durante el ejercicio de su cargo voluntariamente no ejercen el ministerio sacerdotal, ni en privado ni en público, ni dentro ni fuera del país, y este permiso es para un tiempo limitado (Cabestrero 1983: 12-15).

En octubre de 1982, el papa Juan Pablo II puso como condición para realizar su visita a Nicaragua en 1983 que los sacerdotes abandonaran el cargo de ministro. En marzo de 1983, Ernesto Cardenal es amonestado públicamente por Juan Pablo II a su llegada a Nicaragua. El Vaticano exige la renuncia del cargo o de lo contrario se le aplicara el castigo según el Derecho Canónico. ${ }^{4}$ El 5 de febrero de 1985, el Vaticano anuncia por medio

4 Ricardo Peter, Reflections, pág.250: "in 1983, the new Code of Canon Law was approved in which Canon 285.3 prohibited priests from assuming "any public responsibility related to the civil authority". It was simplistic to believe that the bishops would now tolerate the presence of the four priests in the revolutionary government. It was also simplistic to think that the Holy See would accept this situation for very long. The problem became more and more conflictual for all the parties involved."
Religión y política

en América Latina: la confrontación entre Juan Pablo II y Ernesto Cardenal en 1983

Armando Lampe 
Dossier América Latina: política y religión de su vocero el castigo con la "suspensión a divinis" de Ernesto Cardenal, impuesto por Juan Pablo II y, consecuentemente, Cardenal ya no podía ejercer el ministerio sacerdotal. Después de que Cardenal ya no era ministro se mantuvo su suspensión canónica, porque seguía siendo miembro del partido sandinista y apoyando la revolución (Koch 1992: 160). Curiosamente, el nuevo papa Francisco levanta en agosto de 2014 la "suspensión a divinis" del otro sacerdote y político sandinista Miguel D’Escoto, quien fue secretario de Relaciones Exteriores en el gobierno sandinista, y se reintegra al ministerio sacerdotal tras haber escrito una carta al Papa pidiendo permiso para celebrar misa antes de morir. Ernesto Cardenal no hizo tal petición y en una conversación privada en diciembre de 2014 me dijo que no le interesaba volver a ejercer el sacerdocio, pues su vocación no es de sacerdote sino de monje (Cardenal 2005: 308). ${ }^{5}$

\section{La doctrina Rampolla}

Efectivamente, hay una doctrina política del Vaticano constante desde León XIII hasta Juan Pablo II (Mallimaci 2013: 211-244, 241). ${ }^{6}$ Ella inspira los documentos eclesiásticos de la Santa Sede y la conducta diplomática de la Secretaría de Estado y de la nunciatura, y también los textos del Vaticano II, de Puebla, Santo Domingo y Aparecida. Esta doctrina fue creada bajo la dirección del cardenal Rampolla a fines del siglo XIX para dar respuesta a la nueva coyuntura de la política europea, especialmente en Francia, el principal país católico de aquel entonces. La situación a la que corresponde la doctrina Rampolla es la siguiente: en Francia hay cambio de régimen político, la monarquía parece condenada definitivamente y la república se consolida. Con ese cambio desaparece la íntima fusión entre las monarquías católicas y la Iglesia católica, que había sido la base de la doctrina política romana durante los siglos anteriores, y la Santa Sede tiene que convivir con el gobierno republicano. Esa doctrina, conocida como la política de ralliement, fue concebida por el carde-

5 Aquí Ernesto Cardenal repite la opinión ya publicada: "Más o menos al año de la visita del Papa los sacerdotes con cargos en el gobierno fuimos sancionados por el Vaticano, como ya nos venían amenazando que lo harían si no dejábamos esos cargos. Al padre Miguel Escoto y a mí nos prohibieron la administración de sacramentos, y a Fernando mi hermano lo expulsaron de la Compañía de Jesús. Escoto cuenta que cuando le prohibieron celebrar misa estuvo llorando toda la noche. Ése no fue mi caso. Mi vocación no había sido sacerdotal sino monástica. A mí no me atraía la pastoral, ni la administración de sacramentos, ni ningún tipo de actividad parroquial. Al salir del monasterio trapense, por el consejo de Merton, estudié para el sacerdocio sólo con miras a la fundación de una pequeña comunidad.”

6 Presente también en Benedicto XVI con su tesis de "Entweltlichung" de la Iglesia, es decir, separar a la Iglesia del mundo que está por encima de todos los intereses mundanos, e inclusive en el papa Francisco cuando dijo: "En la sociedad, la Iglesia pide una sola cosa con una claridad particular: la libertad de anunciar el evangelio de manera integral, incluso cuando esto esté en oposición con el mundo” (ante los obispos reunidos en Río de Janeiro en 1983). 
nal Rampolla, Secretario de Estado de 1887 a 1903 bajo el pontificado de León XIII, quien fue papa de 1878 a 1903 (Ward 1964: 60-73).7

Mariano Rampolla del Tindaro nació el 17 de agosto de 1843 en Sicilia en una familia aristocrática (Hammecke 2010: 31-38). Después de su ordenación sacerdotal en 1866 hizo su doctorado en Derecho Canónico que terminó en 1870. Fue miembro de la Academia de los Nobles Eclesiásticos ("Accademia dei Nobili Ecclesiastici"). En 1875 fue secretario de la Nunciatura en Madrid, apoyando al Nuncio Giovanni Simeoni (1816-1892), quien fue nombrado en 1876 como Secretario de Estado de la Santa Sede. Rampolla fue nombrado en Roma como secretario de la Congregación para los Ritos Orientales y en 1880 secretario de la Propaganda Fide. De 1882 a 1887 fue nuncio en Madrid y escogió a Mons. Della Chiesa, quien fuera después el papa Benedicto XV, como su secretario y quien también fue egresado de la "Accademia dei Nobili". En 1887 fue nombrado Secretario de Estado por León XIII, con la instrucción de dar atención especial a América Latina (Pazos 2006: 243-250). A partir de 1887 Rampolla desarrolla la política de "ralliement", un acercamiento del catolicismo francés a la República de Francia sin la demanda de un restablecimiento de la monarquía, aceptando que la Iglesia está por encima de los partidos y que pueda colaborar diplomáticamente con diversas formas de gobierno. Rampolla, quien falleció en 1913, es considerado el iniciador y el constructor de ese cambio en la política exterior del Vaticano (Koelliker 2006: 125-137). ${ }^{8}$

Es considerado también un mediador exitoso: por ejemplo, en 1885 entre Alemania y España por las Islas Carolingas, que fue una petición explícita de Bismarck; en 1890 entre Inglaterra y Portugal por Congo; en 1891 entre Perú y España por la diferencia del arancel de aduanas, y en 1894 entre Inglaterra y Venezuela a petición de Venezuela (Levillain, Ticchi 2006: 3-8). Rampolla desarrolló una intensa actividad diplomática con todo tipo de Estados, pero no pudo evitar la guerra en 1898 entre España y Estados Unidos. El asunto para Rampolla es únicamente la relación entre Iglesia y Estado en el nuevo contexto republicano. No es un problema de sociedad ni de la relación entre la Iglesia y la sociedad global. Ni las luchas sociales, ni el carácter de clase de los partidos políticos entran en la consideración de la doctrina Rampolla. Frente

7 James E Ward cita en la página 64 el embajador de Francia ante la Santa Sede, quien comentaba que el tema favorito de Rampolla era un mayor entendimiento entre Francia y la Santa Sede, plasmado en la encíclica 'Sapientiae Christianae' (1890); "though proclaiming the rights of the Church as a perfect society however established that she will not be made subservient to any political party nor will she pass judgment either on the form or institutions by which nations intend to be governed or on different systems of government. In resumé, this is a very distinct and energetic affirmation of the idea which Cardinal Rampolla has emphasized in different conversations with me."

8 Laurent Koelliker reconoce que la política de ralliement no tuvo éxito en ese tiempo, pero "Léon XIII a permis à l'Église de retrouver une place au sein de l'Europe politique, préparant ainsi le Saint-Siège à affronter les défis politico-diplomatiques du XXe siècle.”
Religión y política

en América Latina: la confrontación entre Juan Pablo II y Ernesto Cardenal en 1983

Armando Lampe 
Dossier América Latina: política y religión al establecimiento de un Estado republicano con régimen de partidos y de elecciones, la doctrina Rampolla enuncia los siguientes principios:

a) La Iglesia acepta la distinción entre lo "religioso" que es de su incumbencia, y lo "político" que es de la incumbencia de los partidos políticos y del Estado, independiente de la Iglesia (Bach 1987: 17). Existen terrenos mixtos en los que se busca un acuerdo o modus vivendi (familia, educación, bienes materiales de la Iglesia). Pero en lo político la Iglesia se declara neutral y deja que los católicos puedan hacer sus opciones libremente. Consecuentemente la Iglesia tiende a evitar que los sacerdotes y obispos ocupen funciones dentro del Estado, aunque siempre se admitieron excepciones en todos los países católicos.

b) La Iglesia busca acuerdos explícitos (Concordatos o modus vivendi) con todos los gobiernos (Coppa 2008: 102). La relación Iglesia-Estado se define por acuerdo entre la Santa Sede y los Estados nacionales sin pasar por las iglesias locales y los episcopados nacionales. La diplomacia romana parte del principio de que es necesario obtener del Estado las condiciones más favorables posibles para su acción en todas las areas mixtas, sobre todo los bienes materiales de la Iglesia, la familia y la educación. En cambio, la Santa Sede se compromete a exigir de las Iglesias nacionales lealtad y apoyo a los gobiernos que hacen los acuerdos. A las Iglesias nacionales no se les deja iniciativas: se les pide que actuen dentro del marco trazado por los acuerdos entre Roma y los gobiernos. La base de esta política es que la Iglesia necesita paz y tranquilidad y acuerdo con los gobernantes para funcionar normalmente. El valor supremo para la Iglesia es el desempeño normal de sus actividades tradicionales y de sus derechos institucionales.

c) Los católicos, es decir los laicos, son invitados a actuar dentro de las instituciones previstas por el régimen político de modo tal que puedan conseguir para la Iglesia las condiciones exteriores de acción, las más favorables posibles (por ejemplo, la lucha contra el divorcio, a favor de la enseñanza católica, de la libertad religiosa y de la ayuda financiera del Estado a las instituciones católicas). Los partidos conservadores han asumido esta tarea, pero los partidos demócrata-cristianos nacidos de ellos a pesar de un enfoque social mucho más marcado, han tenido que asumir la misma tarea en continuidad con los antiguos partidos conservadores. ${ }^{9}$

Todo esto no es doctrina de fe, sino doctrina política: esquema de acción adaptado a una situación determinada a partir de una apreciación de la situación y de los desafíos fundamentales de la Iglesia. Al prohibir al sacerdote Cardenal de ocupar una función en el poder ejecutivo, Juan Pablo II estaba

9 Hay una continuidad de pensamiento que va de Rampolla, della Chiesa, Ratti, Pacelli, Montini, hasta cardenal Benelli quien fue capellán de la democracia cristiana internacional y que por poco fue electo papa en 1978. Por otra parte está la extrema cautela y neutralidad de la diplomacia vaticana que se remonta al cardenal Gasparri, inspirada en la doctrina Rampolla: "la Iglesia debe abstenerse de un compromiso directo con un partido determinado, y sobre todo de la lucha política entre los partidos." (Riccardi 1987: 217-231, 219) 
aplicando la doctrina Rampolla. Una doctrina política no es ni falsa ni verdadera, sino relevante o irrelevante. La pregunta entonces es si fue relevante para el caso de Nicaragua.

\section{El caso excepcional de Nicaragua}

Esa doctrina fue irrelevante para la situación de Nicaragua donde se exigía otro esquema de acción. El mismo embajador de Nicaragua ante el Vaticano entre 1980 y 1990 escribe:

For the government it was an exceptional presence due to the emergency period in which the country found itself. Basically the presence of the four priests was designed to be limited and temporary, but it was impossible to forecast the duration of their responsibilities in the government (...). The government needed the competence of some of them and the international prestige of others. (Peter 1994: 249-250)

El embajador refería indudablemente al prestigio internacional de Ernesto Cardenal, para quien la participación en el gobierno sandinista era un asunto de principio.

Según el pensamiento de Ernesto Cardenal, la base de la vida nacional fue el antagonismo radical entre un sistema dictatorial de opresión y una lucha de liberación. El Estado de Seguridad Nacional bajo Somoza en Nicaragua estaba hondamente comprometido con el sistema de dominación. La Iglesia no podía estar implantada en la sociedad sin definirse en relación con ese conflicto fundamental, según Cardenal. No fue una cuestión de partidos políticos más o menos equivalentes, sino que había solamente dos partidos fundamentales, el partido de la opresión, que fue el régimen somozista, y el partido de la liberación, que fue el movimiento sandinista, y Cardenal se unió al movimiento sandinista.

El teólogo Cabestrero es de la opinión de que debe haber excepción a la regla, pero no cuestiona la regla de la prohibición de sacerdotes para asumir cargos políticos. No puede dar un juicio por cuánto tiempo se debe postergar el estado de excepción, hay que tomar más bien en cuenta las circunstancias concretas, y el prerrequisito es que siempre debe haber diálogo (Cabestrero 1983: 15). También el otro sacerdote en el gabinete sandinista Fernando Cardenal acepta esa lógica de la excepción; no cree que en todas las revoluciones de América Latina los sacerdotes deben ocupar puesto de ministro en el gobierno, sólo la revolución de Nicaragua era una excepción (Cardenal 1982: 516-522, 521). Repite esa opinión en sus memorias:

Mi posición era que aceptaba el Canon 285 del Derecho Canónico que prohíbe a los sacerdotes trabajar en puestos de gobierno o en cargos en par-
Religión y política en América Latina: la confrontación entre Juan Pablo II y Ernesto Cardenal en 1983

Armando Lampe 
Dossier América Latina: política y religión tidos políticos. Me parecía que estaba bien como cosa normal. Pero creía que en Nicaragua se daban una serie de circunstancias muy especiales que justificaban nuestro trabajo en la revolución como una excepción extraordinaria. Pensaba que todas las revoluciones se habian hecho en la historia sin los cristianos, a pesar de los cristianos o contra los cristianos, y la sandinista era la primera revolución que se hacía con una profunda y amplia participación de los cristianos. Nuestra presencia como sacerdotes en la revolución se volvía enormemente importante para Nicaragua y para la historia de la Iglesia de América Latina. (Cardenal 2008: 180) ${ }^{10}$

Ernesto Cardenal motivaba el caso excepcional de Nicaragua de la siguiente manera:

Nosotros considerábamos que estábamos teniendo un rol histórico con nuestros cargos de gobierno en la revolución de Nicaragua. Sacerdotes en politica no era novedad en la Iglesia, ni obispos y papas en política. Pero era la primera vez en la historia que había sacerdotes en una revolución. Todas las revoluciones anteriores habian sido sin los cristianos o contra los cristianos, y ésta era la primera vez que se hacía con el apoyo masivo de los cristianos. Y pensábamos que ello influiría en las revoluciones del futuro, $y$ aún en revoluciones del pasado como la cubana. Nuestra desobediencia al Vaticano fue por obediencia a nuestra conciencia; y teníamos presente lo que dice santo Tomás de Aquino: que la autoridad suprema es la propia conciencia, y que a veces es necesario oponerse al mandato del Papa siguiendo la propia conciencia, aún a riesgo de ser excomulgado. (Cardenal 2005: 310)

${ }^{10}$ En cuanto a la situación canónica del padre Fernando Cardenal: el 12 de octubre de 1984 el superior general de la Compañía de Jesús, el Padre Kolvenbach llega al final del proceso en su carta: "Ud. apeló a su propia conciencia, que le urge a seguir un camino diverso. Ciertamente todos los jesuitas deben respetar su objeción de conciencia, aunque la Compañía no puede compartirla. Si Usted cree que en consecuencia no debe abandonar esa responsabilidad de gobierno, sería normal que pidiera dejar la Compañía. Para Usted y para todos nosotros sería una decisión dolorosa; pero sería consecuente con la naturaleza de su presente compromiso y tendría el respeto, el apoyo y la simpatía de todos" (pág. 198). Fernando Cardenal responde que no tenía ninguna razón para salir de la Compañía de Jesús, tenía objeción de conciencia y que tendrían que sacarlo de la orden. (pág. 203) A fines de octubre de 1984 vino el decreto de su expulsión de la orden (p. 204). En 1990, el padre Kolvenbach comunica a Fernando que estudió su expediente y que había encontrado una auténtica objeción de conciencia y que pueda entrar de nuevo en la Compañía de Jesús, el primer caso en más de 460 años de historia de la Compañía de Jesús, en que un expulsado de la Compañía regresara a la Orden (pág. 254). En el mes de junio de 1996 empezó de nuevo el noviciado en San Salvador y en junio de 1997 hizo en Managua los primeros votos, y el 24 de marzo de 2004 hizo los últimos votos en Managua e ingresó definitivamente a la Compañía de Jesús. Con esto se cerró un capítulo de conflictos con las autoridades eclesiásticas que había durado cerca de 25 años (pág. 258). 


\section{La política en Nicaragua}

La política en la Nicaragua de Somoza, caracterizada por Ernesto Cardenal como un caso excepcional, fue algo muy diferente de la política basada en la actuación de partidos políticos. Con el apoyo de Estados Unidos Anastasio Somoza, quien era jefe de la Guardia Nacional, asumió el poder en Nicaragua en 1936 y estableció una dinastía familiar que duró hasta 1979, misma que se volvió un bastión de supuesta estabilidad anticomunista (Weckel 2009: 167-182, 168). Dos años antes, en 1934, mandó asesinar a César Augusto Sandino, quien era el jefe de la rebelión campesina contra la ocupación americana. En Nicaragua en esa época los partidos políticos tuvieron una actuación de menor importancia; en cierto sentido se puede decir que existían sólo dos "partidos" verdaderos: las Fuerzas Armadas y la Iglesia católica.

En esa Nicaragua no había lugar para un partido político, estaba polarizada por la revolución, que significaba optar por un cambio de sociedad o mantener la dictadura militar. Por un lado, había una red de intereses que quería mantener el status quo, los privilegios y las desigualdades, y que se sustentaba en el Ejército, o sea, los oficiales de las Fuerzas Armadas bajo la guía de la dinastía Somoza. La función del Estado somozista fue impedir una revolución y para esto se valió de la represión. Por otro lado estaba la guerrilla organizada en el Frente Sandinista de Liberación Nacional (FSLN), quien no tenía ninguna posibilidad de llegar jamás a ejercer el gobierno por medios constitucionales. La única posibilidad que tenían fue la revolución armada con la cual lograron derrocar a Somoza en 1979.

Ernesto Cardenal escribió acertadamente que los dos grandes logros de la revolución sandinista fueron derrocar a Somoza en 1979 y reconocer la derrota electoral del FSLN en 1990, que fue convertido en partido político. "El principal logro de la revolución fue la democracia, aunque no era esto lo que la revolución quería de tendencia socialista. Las elecciones fueron tan libres y honestas que las perdimos. La revolución de Nicaragua ganó perdiendo las elecciones de 1990" (Cardenal 2005: 444). La derrota electoral, desde la perspectiva de Ernesto Cardenal, había sido una victoria moral para la revolución sandinista.

No sólo la situación política era excepcional, sino también la religiosa, según Ernesto Cardenal, donde la revolución requería la participación de sacerdotes. La Nicaragua de Somoza fue el caso de un pueblo católico profundamente oprimido, pero oprimido por otro grupo católico, es decir, la misma religión fue la de los dominadores y la de los dominados. Fue un mismo conjunto de símbolos y un lenguaje común, pero ese sistema fue vivido de modo muy diferente por el pueblo y por su élite dominante. Las dos funciones de la religión católica desempeñaban dos papeles políticos muy diferentes.

Para la élite, la religión católica cumplía con un papel de legitimación. Los dirigentes somozistas invocaban a Dios y se sometían formalmente a la Iglesia católica, a sus leyes, ritos e instituciones. La religión proporcionaba
Religión y política en América Latina: la confrontación entre Juan Pablo II y Ernesto Cardenal en 1983

Armando Lampe 
Dossier América Latina: política y religión signos para los momentos importantes de la vida de las familias y de la nación. La religión católica fue la religión del Estado de modo mucho más importante que en Europa. La separación entre la Iglesia y el Estado es más bien una ficción jurídica que una realidad, porque en realidad la unión es muy estrecha. El Estado somozista hacía todo lo posible para estrechar más todavía las relaciones y poner a la Iglesia al servicio de su legitimación. Sin embargo, ni a la religión ni al clero se les atribuía ningún papel en la conducción del Estado somozista. A la doctrina social de la Iglesia no se le daba ningún valor práctico; se celebraba pero no se aplicaba. Había una separación total en cuanto a los valores y la conducción política. A los sacerdotes se les pedía reconocimiento, pero ninguna opinión.

En cuanto a los dominados, la religión ocupaba en su vida y su cultura una parte mucho más importante. En general, dominaba la religión en medio de su cultura: ritos, fiestas, relaciones sociales, todo se refería a la religión y encontraba en ella su sentido. Es que ni la vida política, ni la cultura nacional ni la vida económica estaba al alcance de los pobres. Marginados de la vida nacional, sólo les quedaba la religión. Las motivaciones de la vida tenían que ser siempre religiosas. Los únicos líderes en quienes confiaban eran los líderes religiosos, sacerdotes y pastores. Otros líderes eran explotadores o traidores y no podían contar con ellos. Si algunos venían al pueblo, era muchas veces para engañarlos o robarlos.

Los sacerdotes eran los líderes políticos, económicos y culturales. Había un abismo entre lo que pueblo esperaba de un sacerdote y lo que debe ser un sacerdote como lo determinaba el Derecho Canónico. Lo que el sacerdote quería como organización del pueblo, lo lograba por su prestigio nacional. Si quería un liderazgo político, organizar un sindicato, una campaña de alfabetización, una cooperativa, un colegio, o un grupo juvenil, lo lograba. Bastaba con tomar la iniciativa y tener cierta capacidad de organización. En una situación de ausencia casi total de organización más allá de la familia, todo sería bien acogido por el pueblo que consideraba a sus sacerdotes como a sus jefes naturales. La revolución sandinista fue un movimiento con motivaciones cristianas, animado por sacerdotes, como fue el caso de Ernesto Cardenal (Löwy 1996: 94-102).

Por toda esa situación política y religiosa excepcional de Nicaragua, el esquema de la doctrina Rampolla, que exigía una neutralidad política a los sacerdotes, resulta irrelevante, según el desarrollo lógico del pensamiento de Ernesto Cardenal. La Iglesia misma ha admitido excepciones en este tipo de situaciones y ha permitido a sacerdotes que ocupen funciones dentro del Estado en países católicos, cuando se trata de una situación de una dictadura dónde, además, las condiciones no son favorables para que laicos asumieran liderazgo político (Bach 1987: 244). Fue justo esa argumentación que llevó a los obispos nicaragüenses en otorgar en 1981 el permiso a los sacerdotes para ocupar cargos de ministro en el gobierno sandinista dentro de la vigencia del Código de Derecho Cánonico de 1917. Ernesto Cardenal tenía razón en decir que 
su status clerical estaba en orden hasta enero de 1983, pero a partir de enero de 1983 la situación cambió por el nuevo Codex donde sólo el Pontífice podía otorgar una dispensación y por el gesto público de rechazo por parte de Juan Pablo II se podía concluir que a Cardenal le fue negado esa dispensación (Lampe 2013: 109).

A Ernesto Cardenal, siendo sacerdote de una Iglesia comprometida con una opción preferencial por los pobres, el problema político se le presentó en diferentes niveles: el de la movilización popular, el de la organización popular y el de la guerrilla sandinista. Respecto a la concientización y movilización popular, el papel de la religión y del clero fue decisivo en la revolución sandinista. La guerrilla fue asunto de una élite y no tenía contacto con las grandes masas. La religión fue la gran fuerza capaz de dar motivaciones fuertes y líderes escuchados. Pero no toda forma de religión puede desempeñar ese papel liberador, porque existe una religión manipulada o controlada por las clases dominantes que sirve para desmovilizar, para desestimular toda acción política y social (Maduro 1980). En Nicaragua la religión asumió un papel liberador, como muestra la consigna: "Entre cristianismo y revolución no hay contradicción", que resultó la mayor fuerza de la movilización sandinista.

Respecto a la organización popular, el papel del clero fue importante. Fue un pueblo sin élites, sin personas formadas para asumir el liderazgo. Fueron muy pocos los intelectuales que se pusieron a disposición del movimiento sandinista. De allí surgió una misión específica del clero para dar a conocer y divulgar el movimiento sandinista dentro de las masas. Una participación activa en la organización popular fue parte del papel político de la Iglesia popular, definida como Iglesia a favor del pueblo oprimido. Por causa de la brutal represión de los laicos, éstos tenían menos espacio de maniobra que los curas. Y los laicos no alcanzaban el nivel de prestigio popular que tenían los curas, como Ernesto Cardenal, quien tenía enorme prestigio no sólo a nivel nacional, sino también internacional. ${ }^{11}$

Tradicionalmente, la oposición revolucionaria tenía prejuicios muy fuertes en contra de la religión y la Iglesia católica. Sin embargo, con el surgimiento de la teología de la liberación se produjo un cambio y los mismos revolucionarios buscaron contacto con los curas que siguieron esta línea. La experiencia del papel de la Iglesia popular en la revolución de Nicaragua fue clave. El clero no hizo la conducción política del movimiento sandinista, pero pudo influir en el diálogo entre las masas y los intelectuales orgánicos como Carlos Fonseca del FSLN. De hecho, el jesuita Fernando Cardenal narra con todo lujo de detalle cómo los líderes sandinistas establecieron el contacto con sacerdotes para que éstos ingresaran al movimiento revolucionario armado (Cardenal 2008).

El caso de Nicaragua mostró que la religión ya no fue considerada un obstáculo y enemigo en la transformación de la sociedad por esos intelectuales revolucionarios. Todo ese análisis de los hermanos Cardenal sobre la unicidad de la
Religión y política en América Latina: la confrontación entre Juan Pablo II y Ernesto Cardenal en 1983

Armando Lampe

${ }^{11}$ Su prestigio internacional es por su obra literaria, véase: (García González 2011). 
Dossier América Latina: política y religión revolución sandinista, en el sentido de que fue una revolución con participación de cristianos y sacerdotes, es clave para entender por qué Ernesto Cardenal no quiso renunciar a su puesto de ministro del gobierno sandinista a pesar de que le llegó la orden por Juan Pablo II para que se retirara de ese cargo.

\section{Conclusión}

La situación de Nicaragua no se definía por formas políticas clásicas como en Europa y América del Norte, porque la vida política no consistía en un juego de partidos que luchaban para ocupar los puestos dirigentes de la administración del Estado, sino en un conflicto radical entre un sistema opresor, del cual el Estado somozista fue parte, y las fuerzas sandinistas de liberación de un pueblo oprimido. Exigir que la acción política sea de los laicos y no de sacerdotes no tenía efecto real, porque la vida de partidos fue ficticia. Ella no constituía una verdadera acción cristiana en lo político, la verdadera acción política se ubicaba en otro nivel, en el nivel de la lucha armada sandinista, según Ernesto Cardenal. En tal situación, no se aplica el esquema del régimen republicano que formaba la base de la doctrina Rampolla y que exigía a los sacerdotes no ocupar cargos políticos, aunque Juan Pablo II decidió lo contrario al no reconocer el carácter excepcional del caso donde existía una dictadura y dónde se exigía a sacerdotes asumir cierto liderazgo.

Ya hubo en la historia de la Iglesia situaciones muy diferentes de la situación contemplada por la doctrina Rampolla. Por ejemplo, hubo situaciones de pueblos católicos oprimidos, como fue el caso de la Polonia de Juan Pablo II. Tales ejemplos históricos proporcionan analogías históricas más interesantes que la situación de Europa occidental o América del Norte. Vale la pena estudiar cómo la Iglesia, el clero y los episcopados han actuado en la Polonia comunista dentro de una situación de pueblo católico oprimido (Żaryn 2004: 118-138). En forma general ya encontramos en la Polonia de entonces datos de una Iglesia que apoyaba las organizaciones, como Solidarność, que luchaban contra el régimen comunista, aunque la Iglesia nunca reconoció un partido como católico ni dio apoyo oficial o no oficial a ningún partido (Kuk, 2004: 150-171). Juan Pablo II no pudo ver que la situación de Nicaragua era parecida a la de Polonia, en ambos casos se trataba de un pueblo católico oprimido por una dictadura. El papa pensaba que la revolución sandinista representaba una amenaza comunista y exigió a los sacerdotes abandonar sus cargos políticos.

En cambio, Ernesto Cardenal vio que se trataba de una situación de un pueblo católico oprimido, y que la relación entre la Iglesia y la política se debía establecer de otro modo. En primer lugar, muestra que la religión fue el último refugio de los pobres y el foco de la resistencia. Pues toda la economía estaba al servicio de la familia de Somoza y la política estaba en manos de ella. Lo que le quedaba al pueblo dominado fue su cultura tradicional y su religión. 
En segundo lugar y correlativamente, él como sacerdote tenía que asumir un liderazgo popular y se unió al movimiento sandinista y se volvió su vocero a nivel internacional hasta la caída de Somoza. El clero, además, dirigía las funciones más importantes de la vida social popular, es decir, las religiosas, y, por lo tanto, los sacerdotes eran los líderes naturales. El pueblo consideraba a sus líderes religiosos como a sus jefes políticos reales. Ernesto Cardenal entendió perfectamente bien que el pueblo recurría a él como un jefe en quien confiar, pues asumió una función política que en primer instante no fue ejercicio de alguna función del Estado antes del triunfo de la revolución sandinista, y cuando se dio el triunfo Cardenal mantuvo la función política ahora como una función del Estado. Abandonar esa función en 1983, como lo exigía Juan Pablo II, hubiera significado en ese contexto determinado traicionar al pueblo. Correctamente Cardenal escogió obedecer al pueblo y no al papa.

\section{Bibliografía}

Bach A. (1987), Die politische Betätigung geistlicher Amtsträger nach evangelischem und katholischem Kirchenrecht in der Bundesrepublik Deutschland. Unter der Berücksichtigung der kirchenrechtlichen Entwicklung seit 1918, S. Roderer Verlag, Regensburg.

Cabestrero T. (ed.) (1983), Priester für Frieden und Revolution. Ernesto Cardenal, Miguel d'Escoto, Fernando Cardenal, Peter Hammer Verlag, Wuppertal.

Cardenal E. (1980), Meditation und Widerstand. Dokumentarische Texte und Gedichte. Prólogo de Helmut Gollwitzer, Editado por Hermann Schulz, Gütersloher Verlagshaus Mohn, Gütersloh.

Cardenal E. (2005), La revolución perdida. Memorias, tomo III, Fondo de Cultura Económica, México D.F.

Cardenal F. (1982), Die politische Rolle von Amtsträgern der katholischen Kirche in Nicaragua, "Concilium", no 18, pp. 516-522.

Cardenal F. S. J. (2008), Sacerdote en la revolución. Memorias, tomos I y II, Anamá Ediciones, Nicaragua.

Coppa F. J. (2008), Politics and the Papacy in the Modern World, Praeger, Westport.

Daydí-Tolson S. (ed.) (1998), Del monasterio al mundo: correspondencia entre Ernesto Cardenal y Thomas Merton (1959-1968), Editorial Cuarto Propio, Santiago de Chile.

Fogarty G. P. S.J. (1994), The United States and the Vatican 1939-1984, en: Kent P. C., Pollard J. F. (eds.), Papal Diplomacy in the Modern Age, Praeger, Westport, pp. 221-243.

García González S. (2011), Yo tuve una cosa con él y no es un concepto: originalidad y modernidad en la literatura mística de Ernesto Cardenal, Iberoamericana-Vervuert, Madrid-Frankfurt.

González-Balado J. L. (1978), Ernesto Cardenal: poeta, revolucionario, monje, Ed. Sígueme, Salamanca.

Hammecke R. (2010), Der Kuriale Entscheidungsprozeß zur Neuerung der Papstwahl unter Papst Pius X. Ein Beitrag zur Geschichte des Exclusivrechts, Agenda Verlag, Münster.
Religión y política

en América Latina:

la confrontación entre

Juan Pablo II y Ernesto

Cardenal en 1983

Armando Lampe 
Dossier
América Latina: política y religión
Higgins G. (1982), Die politische Rolle der katholischen Kirche in einem Land mit CommonLaw-Tradition, "Concilium", no 18, pp. 527-531.

Kent P. C., Pollard J. F. (1994), A Diplomacy Unlike Any Other: Papal Diplomacy in the Nineteenth and Twentieth Centuries, en: Kent P. C., Pollard J. F. (eds.), Papal Diplomacy in the Modern Age, Praeger, Westport.

Koch H. H. (1992), Ernesto Cardenal, Edition text + kritik, München.

Koelliker L. (2006), Léon XIII et la Question romaine. Entre triple alliance et alliance francorusse, en: Levillain P., Ticchi J.-M. (eds.), Le Pontificat de Léon XIII: Renaissances du SaintSège?, École Francaise, Roma.

Kuk L. (2004), A Powerful Catholic Church, Unstable State and Authoritarian Political Regime: The Christian Democratic Party in Poland, en: Kaiser W., Wohnout H. (eds.), Political Catholicism in Europe 1918-45, vol. 1, Routledge, Londres.

Lampe A. (2013), Political Celibacy. 1983 as a Turning Point in the Roman Catholic Church for Priests-Politicians, en: Burlacioiu C., Hermann A. (eds.), Veränderte Landkarten, Auf dem Weg zu einer polyzentrischen Geschichte des Weltchristentums, Festschrift für Klaus Koschorke zum 65. Geburtstag, Harrassowitz Verlag, Wiesbaden.

Lemieux R. (1982), Priestertum und Politik - welche Unschuld?, “Concilium”, núm. 18, pp. 465-470.

Levillain P., Ticchi J.-M. (2006), Léon XIII: une vision du monde entre deux siècles, en: Levillain P., Ticchi J.-M. (eds.), Le Pontificat de Léon XIII, Renaissances du Saint-Sège?, École Francaise, Roma.

Liedhegener A. (1960), Macht, Moral und Mehrheiten: der politische Katholizismus in der Bundesrepublik Deutschland und den USA seit 1960, Nomos, Baden-Baden.

Löwy M. (1996), The War of Gods: Religion and Politics in Latin America, Verso, Londres.

Maduro O. (1980), Religión y conflicto social, Centro de Reflexión Teológica, México D. F.

Mallimaci F. (2013), El catolicismo argentino de Bergoglio y el papado de Francisco. Una primera aproximación desde la Argentina, "Sociedad y Religión", vol. XXIII, no 40, pp. 211-244.

Pazos A. M. (2006), Objectifs de la diplomatie vaticane en Amérique Latine à l'époque de Léon XIII, en: Levillain P., Ticchi J.-M. (eds.), Le Pontificat de Léon XIII: Renaissances du Saint-Sège?, École Francaise, Roma.

Peter R. (1994), Reflections on the Nicaraguan Revolution and the Holy See in the 1980s, en: Kent P. C., Pollard J. F. (eds.), Papal Diplomacy in the Modern Age, Praeger, Westport.

Riccardi A. (1987), El Vaticano y el partido político, “Concilium”, no 213, pp. 217-231.

Urdanivia Bertarelli E. (1984), La poesía de Ernesto Cardenal: cristianismo y revolución, Latinoamericana Editores, Lima.

Ward J. E. (1964), The French Cardinals and Leo XIII's Ralliement Policy, "Church History", vol. 33 , no 01 , pp. $60-73$.

Weckel L. (2009), Nicaragua, en: Meier J., Straßner V., Kirche und Katholizismus seit 1945: Lateinamerika und Karibik, Ferdinand Schöningh, Paderborn.

Żaryn J. (2004), In Conflict with the Communist State: the Catholic Church and Catholic Political Organizations in Poland, en: Gehler M., Kaiser W. (eds.), Christian Democracy in Europe Since 1945, vol. 2, Routledge, Londres. 